\section{ECOLOGy OF THE EASTERN POPULATION OF THE SibERIAN CRANE LEUCOGERANUS LEUCOGERANUS IN THE TAIGA SECTION OF ITS FLYWAY: HABITATS, FORAGING, TROPHIC LINKS WITH ELK ALCES ALCES, AND THREATS}

\section{Victor G. Degtyarev ${ }^{1}$ \& Sergei M. Sleptsov ${ }^{2}$}

${ }^{1}$ Head of Laboratory, ${ }^{2}$ Junior Research Worker, Institute for Biological Problems of Cryolithozone, Siberian Branch, Russian Academy of Sciences, 41 Lenin Ave, Yakutsk, 677980, Russia

${ }^{1}$ dvgarea@yandex.ru (corresponding author), ${ }^{2}$ sleptsov@mail.ru

\begin{abstract}
Stopovers along the flyway of the Siberian Crane in the taiga zone of northeastern Asia have not been previously described. In this study, we provide the first investigation of the stopovers of its eastern population in the taiga zone (2006-2011). Seven spring stopovers at bogs were investigated for 10-24 hr each. The birds spent 5-6 hr sleeping at night, while 54-74\% of their time was spent foraging outside the sleep time budget. Based on excreta samples, only 5/109 cranes successfully obtained adequate food during stopovers at typical bogs. Favorable foraging conditions were found at the rare shallow lakes or at Elk Alces alces salt licks where the foraging efficiency was 16 times greater than at bogs unaffected by ungulates. Elk activity led to areas of peat exposure in bogs where the availability of edible grass rhizomes and readily extractable sprouts were increased for the Siberian Crane. Investigations at three autumn stopovers at poor forage riverbeds lasted for $0.3-11.0 \mathrm{hr}$ and were interrupted by boating activities, as were 22 other reported stopovers. Cranes allocated a high proportion of their time to foraging, which they commenced immediately after landing. However, the cranes failed to acquire any significant sustenance during the overwhelming majority of taiga stopovers. Our investigation showed that the eastern population was not specialized in foraging at typical taiga wetlands. Humans indirectly aggravated the naturally harsh migration conditions by overhunting Elk on the flyway and intensive boating activities during the most intense migration period.
\end{abstract}

Keywords: Bog, Critically Endangered, foraging success, time budget, salt lick, stopover.

DOI: http://dx.doi.org/10.11609/JoTT.03467.4871-9 | ZooBank: urn:Isid:zoobank.org:pub:9FF60369-87FD-4D5A-9880-4B2F32EE3BCC

Editor: Crawford Prentice, Nature Management Services, Jalan, Malaysia.

Date of publication: 26 October 2013 (online \& print)

Manuscript details: Ms \# 03467 | Received 29 December 2012 | Final received 10 July 2013 | Finally accepted 09 October 2013

Citation: Degtyarev, V.G. \& S.M. Sleptsov (2013). Ecology of the eastern population of the Siberian Crane Leucogeranus leucogeranus in the taiga section of its flyway: habitats, foraging, trophic links with Elk Alces alces, and threats. Journal of Threatened Taxa 5(14): 4871-4879; http://dx.doi.org/10.11609/JoTT.o3467.4871-9

Copyright: @ Degtyarev \& Sleptsov 2013. Creative Commons Attribution 3.0 Unported License. JoTT allows unrestricted use of this article in any medium, reproduction and distribution by providing adequate credit to the authors and the source of publication.

Funding: The work was supported by the Russian Foundation for Basic Research (the project No. 11-04-00130) and the UNEP/GEF project GF/2712-03-4627.

Competing Interest: Authors declare no competing interests.

Author Contribution: VGD conceived the investigation project, carried out the field work, assembled and analyzed the data, and prepared the manuscript. SMS carried out the field work.

Author Details: DR. VICTOR G. DEGTYAREV was awarded PhD (zoology) and DSc (nature conservation) in 1987 and 2000 respectively. He studies cryogenic wetlands, waterbirds ecology and resources, endangered species (mostly Hooded and Siberian Cranes). SERGEI M. SLEPTSOV is preparing his thesis on tundra waterbirds. He has carried on ongoing research on optimal nesting sites of the eastern population of Siberian Crane in the tundra (the Indigirka River basin).

Acknowledgements: We thank I.D. Pavlov, A.G. Takhvatulin, and N.V. Bushkov for their assistance during our field studies, and A.E. Pshennikov for his assistance in wetland quantification, and L.V. Kuznetsova and V.I. Zakharova for their work in plant identification, and G.W. Archibald for his valuable suggestions and improvement of this manuscript.
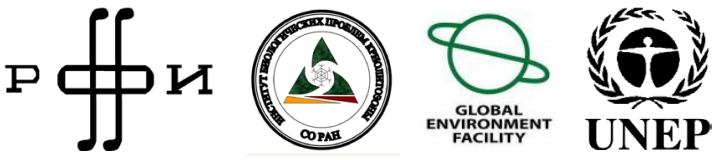


\section{INTRODUCTION}

The Siberian Crane Leucogeranus leucogeranus Pallas, 1773 is one of the largest flying birds (Image 1) and in 2000 it was listed as Critically Endangered (Birdlife International 2012). This species is mainly represented by its eastern population of approximately 4,000 individuals. The Siberian Crane's current conservation status was justified by the expected alteration or loss of wintering grounds for the eastern population after the development of the Three Gorges Dam in China (IUCN 2011). Studies of the eastern population have provided some basic knowledge on the species and its population distribution, including the breeding biology, major migration route, wintering habitat conditions, and principal conservation threats (Johnsgard 1983; Potapov \& Flint 1987; Potapov 1992; Meine \& Archibald 1996; BirdLife International 2001; Kanai et al. 2002; Wu et al. 2009). However, details of the Crane's population ecology have not been fully described. In particular, the characteristics of flyway stopovers, as well as the environmental conditions and ecology of the staging wetlands in northeastern Asia remain unknown. For conservation purposes, the lack of such knowledge makes it difficult to assess or predict the population's reaction to probable disturbances during the pre-migration period.

The Siberian Crane is known to be omnivorous and 'the most specialized crane in terms of its habitat requirements, and the most aquatic, exclusively using wetlands for nesting, feeding, and roosting, preferring wide expanses of shallow fresh water with good visibility' and it prefers such habitats in high and low latitudes (Meine \& Archibald 1996). The breeding and wintering habitats differ significantly from the taiga wetlands and it is not clear how this highly specialized population can utilize them, or if it can display omnivorous foraging behaviour. To understand the impact of any disturbance that might affect the pre-migration period, e.g., the development of the Three Gorges Dam in China (Wu et al. 2009), it is important to determine how the flyway environmental conditions allow the population to compensate for lipid reserve shortages. We hypothesized that stenotopy would not allow the population to find favorable foraging conditions during taiga stopovers.

In this paper, we describe and discuss the habitat use, foraging conditions, relationships with Elk Alces alces, foraging success, and the correspondence between the taiga wetlands and the ecological requirements of the eastern population of the Siberian Crane, as well as the impacts of anthropogenic activity along its flyway in northeastern Asia during spring stopovers. This is the first study of Siberian Crane stopovers in the taiga zone.

\section{MATERIALS AND METHODS}

The studies were conducted during 2006-2011 in the basin of the Aldan River (northeast Asia) (Fig. 1). Wetlands along the centerline of the flyway were investigated between $56^{\circ} \mathrm{N}$ and $63^{\circ} \mathrm{N}$. The stopover study area (the lower catchment area of the Maya River, center: $59^{\circ} 4^{\prime} \mathrm{N}$ \& $134^{\circ} 30^{\prime} \mathrm{E}$ ) was selected based on existing data on the flyway used by the eastern population (Kanai et al. 2002), which contained two areas that differed in their degree of human activity.

The studies of the wetlands aimed to determine their typology and structure, as well as an assessment of whether they satisfied the habitat requirements (shallow and muddy area, with wide expanses and typical food resources) of the Siberian Crane's eastern population. We visited 133 wetland points, which corresponded to the categories of lake, bog, or lake marsh-meadow and lakebog complexes. We covered $1500 \mathrm{~km}$ by motorboat or rafting along the main water bodies and five tributaries. Based on a direct inventory of the wetlands in the study area, which was created using ESRI ArcView GIS 3.3 and Landsat 5TM satellite images $(30 \mathrm{~m}$ ground sample distance; acquisition dates, 29 July and 14 August 2010), we roughly quantified the water courses of the wetlands utilized by the study population.

We tested the match between the taiga wetlands and the habitat requirements of the study species based on known ecological characteristics of the population (Potapov \& Flint 1987; Meine \& Archibald 1996; BirdLife International 2001) and by a study of Crane foraging in the Momoge Nature Reserve (northeast China) in October-November 2007 and ongoing research on the population's optimal nesting sites in the tundra (the Indigirka River basin), which revealed technical details of fishing, earthworm searching, plant object extraction, or collection, and the functional structure of the nesting territory.

We monitored three bogs, three floodplain lakes, and three riverine areas for five years during the population's most intense migration period, and on two occasions we performed observations at two other bogs. Systematic observations were made at distances of 100-150 m from the time of arrival of the cranes until they left. We also conducted in depth examinations of two bogs after spring stopovers, where the number of cranes resting and the duration of their stay were known. We also measured the time spent sleeping at night. The time allocated 


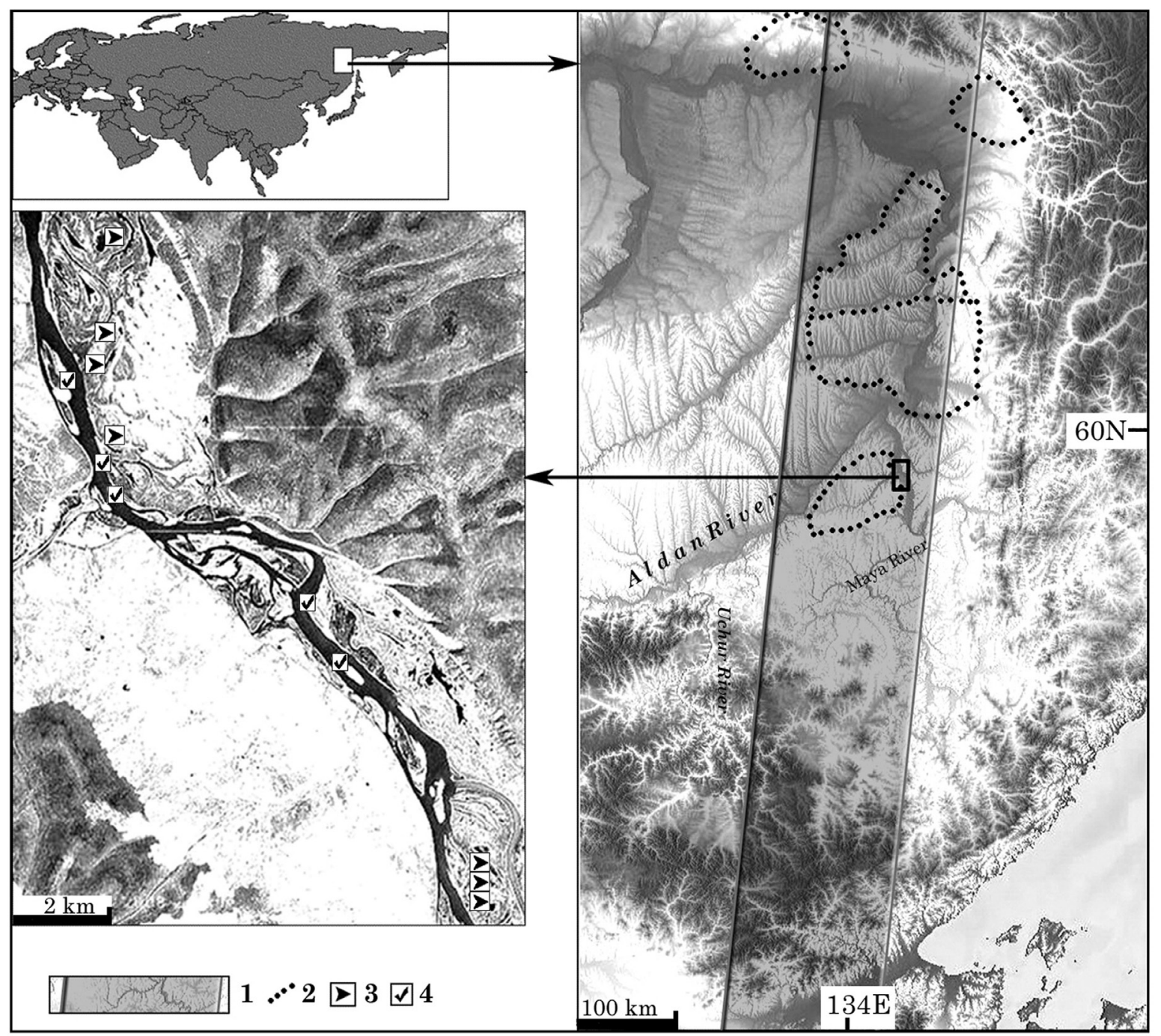

Figure 1. Study area. 1 - Flyway; 2 - Boundaries of local nature reserves; 3 - Location of spring stopovers; 4 - Location of autumn stopovers.

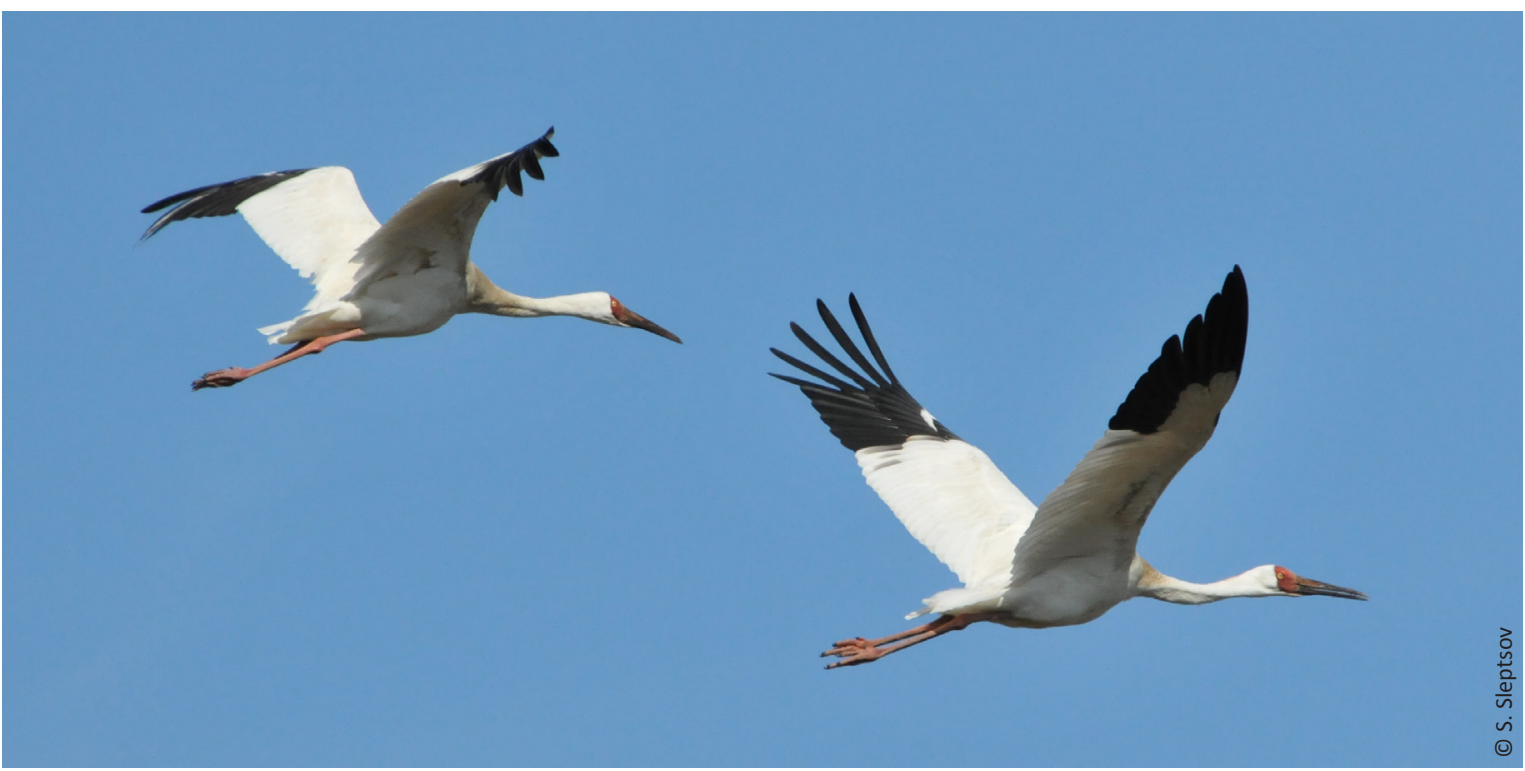

Image 1. Siberian Cranes in flight 
to other activities was quantified using scan sampling. One pair, one family, and six flocks of 11-31 individuals were scanned at 15-minute intervals. The basic diet was determined based on foraging marks, fecal samples, and visual observations of foraging. In addition, we observed and recorded the conditions in eight wetland locations, which had been reported with some degree of certainty as stopover locations during interviews.

The field data on stopover locations was supplemented with interviews with 26 reliable local informants.

\section{RESULTS}

\section{Wetlands utilized by the population}

The Siberian Cranes stopped at marshes around flood plain lakes, at river gravel spits or flats, and at bogs that differed in their distribution, total area, and density (Table 1), as well as extremely rare shallow lakes. All the habitats were $<0.5 \mathrm{~km}^{2}$ in size.

Gravel spits and flats are formed mainly by riverbed outcroppings from low water levels. The majority of the river systems in the study area were mountainous or semimountainous, so low water levels were rarely observed in the autumn during the period of intense migration, while they were never observed in the spring. The water levels and the shallow water available for Cranes fluctuated significantly, because these factors were dependent on hydrological regimes. Thus, areas located on mountain tributaries or the upstream edges of large river islands contained no resources for cranes to feed upon. The land and shallows on the downstream edge of large river islands contained sparse aquatic vegetation, which included Pondweed Potamogeton spp., algae growing on gravel and submerged arboreal substratum, and (rarely) Water Horsetail Equisetum arvense tubers. Small shoals of whitebait (juveniles of common fish species) occasionally approached the shallows. The main streams were intensively used for boating activities. During the period of intense migration in 2010 and 2011, at least one motorboat passed the stopover study site per hour between sunrise and twilight. All of the stopover locations along the main stream were passed by boats at distances of $<300 \mathrm{~m}$.

Marshes occurred around floodplain lakes in gently sloping lake depressions, which were surrounded by unforested lands covered by water meadows. This type of marsh formed a patch with an area up to $3,000 \mathrm{~m}^{2}$ (at one end of an oblong lake) or a belt up to $20 \mathrm{~m}$ wide (between an open lake and a meadow). The marsh vegetation was dominated by sedges, Carex spp. The lakes, meadows,
Table 1. Habitats found in the main stream valley of the stopover study area

\begin{tabular}{|c|c|c|c|c|}
\hline \multirow[b]{2}{*}{ Habitat } & \multirow{2}{*}{$\begin{array}{l}\text { Percentage } \\
\text { of river } \\
\text { valley area }\end{array}$} & \multicolumn{2}{|c|}{ Density per } & \multirow{2}{*}{$\begin{array}{l}\text { Maximum } \\
\text { size }\left(\mathrm{km}^{2}\right)\end{array}$} \\
\hline & & $\begin{array}{c}\mathbf{k m}^{2} \text { of } \\
\text { valley area }\end{array}$ & $\begin{array}{c}10 \mathrm{~km} \text { of } \\
\text { river }\end{array}$ & \\
\hline $\begin{array}{l}\text { River gravel } \\
\text { spit and flat }\end{array}$ & 3.5 & 0.5 & 1.7 & 0.39 \\
\hline $\begin{array}{l}\text { Marsh and } \\
\text { water meadow }\end{array}$ & 0.7 & 0.1 & 0.2 & 0.24 \\
\hline Bog & 5.3 & 14.7 & 48.9 & 0.16 \\
\hline
\end{tabular}

and marshes formed an elongated area with an area of $\leq 0.2 \mathrm{~km}^{2}$. Adequate forage for Siberian Cranes in the marshes included the roots of hydrophilic sedges and horsetails. In years with wet springs, the flood marshes were covered entirely by water and were unsuitable as stopover points. The potentially suitable habitats were limited by the high water levels of flood plains in valleys surrounding large rivers. Many flood plain lakes served as hunting grounds for waterfowl during spring.

Bogs were ageing successions of cup-shaped lakes, which ranged from a lake surrounded by a narrow bog belt to a larger, continuous blanket bog that completely covered a water body. The resulting irregularity meant that the surface included dry and wet plots, and pools. The vegetation was composed of Hypnum moss, sedges, and horsetails. During the migration period, no insects or other small animals were observed in any noticeable quantity. Frogs spawned during early May in pools of melting snow, before leaving them.

Bogs were widespread throughout the modern taiga flyway. The majority of bogs were flooded but not submerged. Until the end of May, the bog surface was on the ice layer, which bulged with the pressure of water entering the frozen bog from the upper layers, as found in the central Yakutian Plain (Degtyarev 2007). Bog areas that were difficult for humans to access tended to retain a high local density of Elk, which had very important effects on the foraging conditions for the Siberian Crane. From the spring to autumn, Elk used the bogs as foraging grounds, salt licks, and as shelters from bloodsucking insects. The intensive activity of Elk resulted in damage to the topsoil and herbage, exposing peat slush in the bog. In these areas, there was an increased availability of grass rhizomes, which were consumed by Siberian Cranes. The abundance of green sprouts on the bog disrupted by elks during the spring provided further sustenance. Numerous root fragments resulted from the frequent movement, hoofing, and other activities by Elk. In addition, their combination with early warming of the uncovered peat by solar radiation produced superficial, 
Table 2. Basic characteristics of the observed spring stopovers

\begin{tabular}{|c|c|c|c|c|c|c|c|c|}
\hline \multicolumn{2}{|c|}{ Stopover } & \multirow{2}{*}{$\begin{array}{l}\text { Qty of } \\
\text { cranes }\end{array}$} & \multirow{2}{*}{$\begin{array}{c}\text { Bog area, } \\
\left(\mathrm{m}^{2}\right)\end{array}$} & \multirow{2}{*}{$\begin{array}{c}\text { Foraging } \\
\text { area, } \\
\left(\mathrm{m}^{2}\right)\end{array}$} & \multirow{2}{*}{$\begin{array}{c}\text { Stopover } \\
\text { time, } \\
\text { (min) }\end{array}$} & \multirow{2}{*}{$\begin{array}{l}\text { Night sleep } \\
\text { time } \\
\text { (min) }\end{array}$} & \multirow{2}{*}{$\begin{array}{c}\text { Waking } \\
\text { time spent } \\
\text { foraging (\%) }\end{array}$} & \multirow{2}{*}{$\begin{array}{l}\text { Excrement dry } \\
\text { weight per } \\
\text { individual (g) }\end{array}$} \\
\hline No. & Date & & & & & & & \\
\hline 1 & 19-20.v.2006 & 24 & 190000 & 26000 & 760 & 290 & 74 & 0 \\
\hline 2 & 15-16.v.2009 & 15 & 280000 & 22000 & 1460 & 360 & 67 & 2.34 \\
\hline 3 & 16-17.v.2010 & 31 & 38000 & 9000 & 890 & 300 & 66 & 0 \\
\hline 4 & 15-16.v.2011 & 11 & 450000 & 4300 & 650 & 370 & 69 & 0 \\
\hline 5 & 16-17.v.2011 & 2 & 450000 & 3700 & 840 & 385 & 54 & 0 \\
\hline 6 & 16-17.v.2010 & 13 & 190000 & 24000 & 990 & - & - & 0 \\
\hline 7 & 16-17.v.2010 & 28 & 41000 & 10000 & 990 & - & - & 0.15 \\
\hline
\end{tabular}

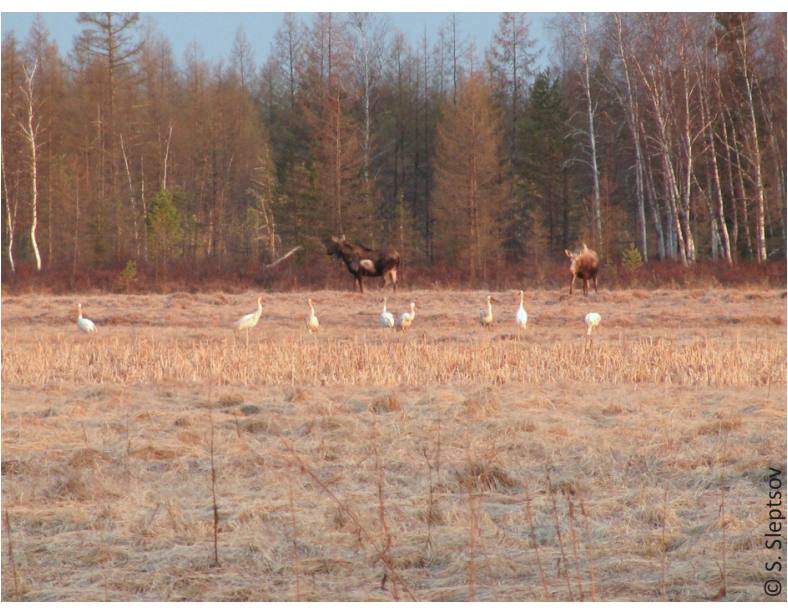

Image 2. Siberian Cranes in salt lick

weakly-rooted and readily extractable sprouts. Bogs and lake-bog complexes were rarely used as fishing or hunting grounds.

We found only three shallow lakes in river valleys where the Siberian Cranes could forage throughout this area. Two lakes were located at the population's migration centerline, where Siberian Cranes could forage by wading during the autumn stopover. These were fishless, oval-shaped lakes with quaking bogs along the edges. One of these was reportedly a regular stopover location for several hundred Siberian Cranes. In 20112012 , this lake almost perfectly met the foraging habitat requirements, i.e., it was relatively spacious $(600 \times 800 \mathrm{~m}$ in area), shallow $(\sim 0.2 \mathrm{~mm}$ depth), with light bottom sediments and well-developed aquatic vegetation. In 2011, it had frozen by 25 September.

\section{Spring stopovers}

All of the investigated spring stopovers were located on bogs (Table 2), where one (Stopover No. 2) was in an area with a high local ungulate density and Elk utilized the bog intensively as a foraging ground and salt lick (Image 2). The remaining stopovers were located in the main stream valley, which had a lower Elk density and less significant impact of ungulates on the bogs.

The Siberian Cranes landed at the observed stopover locations at $16.50 \mathrm{hr}, 18.00 \mathrm{hr}, 18.40 \mathrm{hr}, 19.50 \mathrm{hr}$, and $21.50 \mathrm{hr}$, before leaving at $08.30 \mathrm{hr}, 08.33 \mathrm{hr}, 08.36 \mathrm{hr}$, $10.20 \mathrm{hr}$, and $16.30 \mathrm{hr}$ respectively. At other stopover locations, flocks were recorded landing at $18.00 \mathrm{hr}$, $18.35 \mathrm{hr}$, and $19.50 \mathrm{hr}$, before leaving at $10.45 \mathrm{hr}, 09.30 \mathrm{hr}$, and $11.00 \mathrm{hr}$ respectively. After landing, the Cranes immediately began foraging at their maximum intensity and they continued until they slept at night. They flocked in the bog centre, occupying no more than $25 \%$ of its area and maintaining their distance from the woodlands surrounding the bog. At Stopover No. 2, the Cranes occupied the area that was most extensively affected by ungulates (mostly Elk), foraging for the most part on plots of uncovered peat and peat mud measuring 1-60 $\mathrm{m}^{2}$ in area with a total of about $700 \mathrm{~m}^{2}$. Three Elk intruded in the flock's foraging area and grazed or ate peat matter for four hours nearby, but the cranes were apparently undisturbed.

Visual observations of foraging activity indicated that Siberian Cranes plunged their bills into the peat to extract food from the Hypnum moss layer. They also picked up small objects from the bog surface. Less frequently, moss plucking was followed by pulling rhizomes from the peat. While foraging at the border between the lake and bog surfaces, the cranes sometimes removed peat pieces from the water and extracted then ate rhizomes from those pieces. No activities resembling hunting were recorded. The foraging left marks, with holes in the moss layer measuring $2.5-4.0 \mathrm{~cm}$ in diameter and up to $12 \mathrm{~cm}$ deep along the stems of sedges and Red Cottongrass Eriophorum russeolum. The subterranean parts of grasses (rhizome, root-neck, and 3-4 cm of the stem) were pinched off and absent, while the surface parts 
protruded from the holes. At Stopover No. 2 (the salt lick), we found holes measuring $0.5-1.5 \mathrm{~cm}$ in diameter and up to $3 \mathrm{~cm}$ deep, with bill-tip prints among dense Siberian Crane and Elk footprints, while fragments of green sprouts were observed on the exposed peat and peat mud. The Cranes also turned over the winter nests of voles. The foraging area at Stopover No. 3 had frog spawn on the surface, but the Siberian Cranes did not feed on it.

The Siberian Cranes defecated only at Stopovers No. 2 and No. 7. At Stopover No. 2, the Cranes left 27 droppings with a bright green color and friable consistency. Microscopic analysis of the fecal samples showed that the excrement samples contained vegetable fibers with a few seed membranes or undigested seeds. At Stopover No. 7, the Cranes left five droppings with a brown color and watery consistency, which contained only fibers. In both cases, the droppings included about 1-2 $\mathrm{ml}$ of uric acid excreta.

\section{Autumn stopovers}

During the study period in the autumn, the migrating Siberian Cranes did not stop at the monitored bogs, but they did stop at riverbeds with low water levels during 2010-2012. The stopover by a 46-member flock observed on 29 September was interrupted by a passing motorboat $15 \mathrm{~min}$ after the flock had landed (at 17.30hr). The flock allowed the boat to approach within $500 \mathrm{~m}$. The flock had landed on a low gravel flat, with sand and silt plots at the downstream edge of the island.

A second stopover, by an 11-individual flock (including two juveniles) on a gravel spit, was observed from 2 October to 3 October between $22.20 \mathrm{hr}$ and $07.20 \mathrm{hr}$. After landing, the flock slept for seven hours then began to forage in a creek, shallow silt pool, and gravel. After $50 \mathrm{~min}$, the flock was frightened away by a passing motorboat. The flock flushed when a boat suddenly appeared from an island $100 \mathrm{~m}$ away.

Landing was accompanied by the piercing calls of juveniles. Visual observations of foraging behaviors showed that the cranes picked away at forage in the creek and shallow silt pool, or on the dry gravel surface. One individual tried three times, without success, to catch moving objects in the shallows. The foraging area (about $7,000 \mathrm{~m}^{2}$ ) consisted of a shallow silt pool $\left(3,000 \mathrm{~m}^{2}\right)$ and a dry gravel surface, which was crossed by two 20-40 cm wide creeks. An examination of the foraging area revealed several pondweed stems with pinched-off root-necks and pluck marks in mats with attached algae on the riverbed gravel, and an arboreal substratum that had been uncovered by the decrease in the water level.
Whitebait were the only potential targets for fishing attempts in the shallows. At this stopover, the Cranes left five uric acid excreta measuring about $3-4 \mathrm{ml}$, without excrement.

A third stopover by a pair with a juvenile was observed on $7-8$ October from $18.45 \mathrm{hr}$ until $06.20 \mathrm{hr}$, on a gravel flat by the island. These Siberian Cranes were frightened off three times by motorboats passing at 15 to $20 \mathrm{~min}$ intervals. After each such incident, the cranes flew around for approximately 5-6 min and moved $2 \mathrm{~km}$ away, before returning to the same place. The juvenile emitted piercing calls. Their night sleep commenced at $19.50 \mathrm{hr}$ and was interrupted by the first passing motorboat at 06.20hr. During disturbances, the cranes allowed each of the boats to approach within 300-400 m. The stopover location in silt and sand was overgrown with Water Horsetail while sediment scouring made plant tubers available to the cranes.

\section{Interview results}

Local informants reported sightings (between 1980 and 2012) of Siberian Crane flocks containing up to 50 individuals (about 100 individuals on one occasion, about 200 individuals on one occasion, and about 300 individuals on two occasions), as well as families (3) and solitary juveniles (2) and adult (1) near the main river (20 reports during the autumn and two in the spring), mountain tributaries (four reports in the autumn), a flood plain marsh (one report in the spring), bogs (three reports in the spring and one in the autumn), and a shallow lake (six reports in the autumn). In the riverine areas, cranes were frightened away by passing motorboats at a distance of 200-500 m. The spring stopovers on the main river gravel spits occurred at low water levels, before seasonal ice drifting and floods. There were two records of solitary juveniles immediately before the main river froze; the informants considered it likely that these individuals died shortly thereafter. After visiting 12 reported stopover locations, we found that a marsh, two shallow lakes, two bogs, and four areas by the main stream were typical habitats, which were utilized by Siberian Cranes as described above. However, six of the areas by the main stream were gravel or sand spits that were devoid of any vegetation.

\section{DISCUSSION}

All of the taiga wetlands used by the Siberian Cranes were small- or medium-sized and they were integrated with continuous woodlands, while only the areas by the 
main rivers could be regarded as wide expanses when the area of the water was taken into consideration. This species is specialized for expansive habitats with wide visibility, so they were not able to exploit foraging conditions that were favorable to other species adapted to the taiga wetlands. For example, they never foraged at a mossy larch forest edge during spring stopovers, where the Hooded Crane G. monachus fed on earthworms or at a narrow, dried up watercourse containing fish in numerous shallow pools during early autumn stopovers, which were used by the Grey Heron Ardea cinerea, or berry plantations in woodlands used by the Middendorff's Bean Goose Anser fabalis middendorffii. However, the population forages for earthworms and fish of different sizes throughout the breeding range, as well as for berries.

The bogs were numerous and scattered throughout the migration pathway, and they were regular stopover locations. By contrast, riverine grounds and flood plains were subject to flooding during the period of intense migration. Furthermore, the distribution of such habitats was restricted by the extent of flood plains and the migration pathway crossed through only a limited area. In addition, the bogs yielded sufficient forage for migrating Siberian Cranes. However, this resource was not optimal in terms of availability. When feeding on vegetable matter in optimal foraging conditions, Siberian Cranes readily extract rhizomes or tubers from light bottom sediments in shallow water, wet mud, or marshes. In the taiga bogs, however, the forage (predominantly roots) is buried in peat below a continuous Hypnum moss layer. Such conditions force Siberian Cranes to use foraging techniques that are not normally observed in this species, such as making holes in the moss layer and pinching off rhizomes. The closest known behavior observed at nesting sites involves pinching off the rhizome after plucking the moss from around it. As a result, food extraction was impeded and the food intake was reduced, as shown by the foraging data for Stopovers No. 1 and Nos 3-7. Overall, the majority of individuals failed to achieve any significant sustenance, despite intensive foraging. Based on the excreta collected, only 5/109 Siberian Cranes managed to obtain sufficient food during Stopovers No. 1 and Nos 3-7.

A different level of foraging efficiency was identified at Stopover No. 2, despite its comparable time budget. The quantity of excrement showed that the majority of 15 individuals may have eaten until satiated and they evacuated their digestive tracts twice, while their total weight showed that their foraging efficiency was 16 times greater than the foraging efficiency during the most successful of the stopovers by the group that was described previously. This high foraging efficiency resulted from the high local density and activity of ungulates, especially Elk, which utilized the bog intensively for foraging and salt licks. Weakly-rooted sprouts were the primary forage for Siberian Crane at salt lick stopovers because they were readily extracted from the substratum. Hence, it was clear that Elk activity dramatically affected the functional significance of stopovers. Cranes mainly rested overnight at bogs lacking any Elk impacts and they consumed insignificant quantities of food despite intensive foraging. By contrast, the bogs affected by Elk substantially compensated for the energy costs of migration. In autumn, Siberian Cranes could also find favorable foraging conditions on the extremely rare shallow lakes.

Consequently, Siberian Cranes did not encounter their habitual foraging conditions while migrating across the taiga zone. All of the dominant types of wetland found along the current flyway in the taiga zone failed to meet the specialized ecological requirements of the eastern population and they provided severely limited forage. In the available habitats, the cranes encountered foods that were either highly restricted in quantity or difficult to forage. Migrating cranes made use of a few variations of their foraging methods used at their nesting sites. At first sight, making holes in the moss layer to extract grass subterranean parts was a specific foraging technique determined by the relatively dense moss layer of the taiga bogs. On closer examination, however, both holing and plucking while foraging on moss bogs consisted of the same movements employed by Siberian Cranes in lake shallows at low latitudes, where they dig for tubers from light bottom sediments. It is noteworthy that despite its omnivory, the Siberian Cranes did not feed on frog spawn, but they reacted without success to whitebait movements and winter nests of voles that more accurately conformed to their stereotypical food.

Significantly, Siberian Cranes did not search for stopover locations with favorable foraging conditions. Migrating Cranes made stopovers 1-4 h before twilight. If areas were devoid of appropriate wetlands immediately before nightfall, they continued to fly during the twilight and dark. Thus, the selection of a stopover point was random and the Siberian Cranes only stopped when night began to fall. That accounts for only four stopovers being registered during six years at the three bogs monitored in spring, and during the spring of $2010,20 \%$ of the eastern population passed through the study area, but migrating cranes did not stop near the salt lick in the area where the productive stopover (No. 2) was recorded in 2009 . The 
high proportion of waking time allocated to foraging and the immediate commencement of foraging after landing showed that Siberian Cranes arriving at stopovers needed to replenish their energy requirements. This was also suggested by the piercing calls of juveniles, which aimed 'to solicit feeding by their parents' (Meine \& Archibald 1996). The unfavorable environmental conditions that dominate the taiga wetlands in the Siberian Crane's flyway accounted for the winter migratory patterns of satellite-tracked individuals from the eastern population (Kanai et al. 2002), which consisted of a fast passage over the taiga zone, with its poor forage, and long stopovers at low latitude wetlands, which provided good foraging conditions. The majority of the population could migrate via the taiga zone, having accumulated sufficient fat reserves during the pre-migration periods at wintering or breeding grounds. This is exemplified by data obtained on the fat reserves of three migrating Siberian Cranes. Two adult cranes that had traversed at least $20 \%$ of their entire migration distance to the wintering grounds before dying of lead poisoning in the autumn (Pshennikov et al. 2001) still had 20-25\% body fat at autopsy. On 4 November 1996, an adult bearing the PTT No. 25328 was killed in the wintering range, which weighed $5.6 \mathrm{~kg}$ (Hu 1998). On 29 July, about three months earlier (Kanai et al. 2002), we had weighed the same individual in the breeding range at $7.15 \mathrm{~kg}$. Prior to the start of the migration (middle of September-early October), it must have gained several hundred grams. Thus, the crane lost approximately $2 \mathrm{~kg}$ (30\% of body mass) while migrating to the wintering grounds. We challenge the assumption that arduous migrations are the principal factor that causes natural mortality in juveniles passing over the taiga for the first time, especially in years with unfavorable pre-migration conditions.

The harsh natural conditions of taiga stopovers for the migrating eastern population are affected unfavorably by human-related activities. In the study region, the Elk population has been overhunted in all accessible areas, especially the main river valleys where intensive hunting has decreased the Elk density to the point that bogs are no longer impacted significantly by this ungulate. Thus, a stopover on bogs altered by Elk is currently unfeasible for most of the eastern population of Siberian Crane migrating along the main river valleys. High boating activity has also affected the population's migrating conditions. In years with low water levels, when the population makes stopovers along the main rivers, these stopovers are interrupted by boating. This impact appeared abruptly about 20 years ago, when reliable and powerful outboard boat engines came onto the national market.
We do not envisage any practicable methods to mitigate the disturbance to Siberian Cranes on the main river stopovers. The width of the river in the region, especially at low water levels, impedes any attempt to pass a stopover without disturbing the cranes. Motorboats are the only mode of short-distance transportation that are entirely accessible to the locals. Purchases of boat engines are rising steadily throughout the region, so disturbances will become more frequent. Furthermore, management of the Elk population to maintain an appropriate population density in the region can scarcely be addressed at present.

The beneficial effect of ungulate activity on the primary habitat of the Siberian Crane in the northeastern Asian part of the flyway suggests that appropriate measures can be undertaken to improve stopover foraging conditions. Simple procedures aimed at exposing peat formation in bogs along the Siberian Crane migration routes might facilitate the passage for weaker Cranes (in the worstcase conservation scenario). This would be identical to impact on ungulates on this substrate, so this method is ecologically permissible. Such wetland management procedures could be implemented in at least four regional nature reserves along the taiga flyway (Fig. 1). Considering the random character of stopover range selection, any improvement to the foraging conditions in certain bogs would be worthwhile if combined with luring techniques based on decoys and callers. Migrating Siberian Cranes could also be lured to draw them away from areas near the main river stopovers to appropriate nearby wetlands, where they will not be disturbed by boating.

\section{CONCLUSION}

Thus, the eastern population of the Siberian Crane is not specialized for foraging in the taiga wetlands. Its stenotopy limits any possibility of omnivory during the overwhelming majority of taiga stopovers. This population probably developed without any pressure from the environmental conditions found in taiga wetlands. Humans indirectly aggravate the naturally harsh conditions for migration by overhunting Elk along the flyway and by intensive boating during the most intense migration period. Consequently, the passage through the taiga zone may be the most demanding point in the annual cycle for the eastern population. The possession of sufficient fat reserves has critical importance in such conditions.

These findings provide new insights into the problem 
of the degradation of wintering habitats. The loss of important wintering habitats or any disturbances during the pre-migration period will reduce the reproductive capacity of large birds (Ankney et al. 1991). But the majority of the eastern population of Siberian Cranes will inevitably be threatened by difficulties when passing through the taiga zone, especially when the migrants pass over the two mountain ranges in the area. The vulnerability that results from the eastern population's ecological specialization will make the passage through the taiga harder for weaker individuals. In this worstcase conservation scenario, stopover management might facilitate the passage of Siberian Cranes, including the improvement of foraging conditions.

\section{REFERENCES}

Ankney, C.D., A.D. Afton \& R.T. Alisauskas (1991). The role of nutrient reserves in limiting waterfowl reproduction. Condor 93: 1029-1032. BirdLife International (2001). Threatened Birds of Asia: the BirdLife International Red Data Book. BirdLife International, Cambridge, UK, $3026 p p$.

BirdLife International (2012). Leucogeranus leucogeranus. In: IUCN 2013. IUCN Red List of Threatened Species. Version 2013.1. <www. iucnredlist.org>. Downloaded on 19 October 2013.
Degtyarev, V.G. (2007). Effect of deep freezing of lakes on food supply in habitats of waterbirds. Russian Journal of Ecolology 6(38): 408412; http://dx.doi.org/10.1134/S1067413607060057

Hu, Y.X. (1998). One Siberian Crane mounted with a satellite tracing radio transmitter was killed. China Crane News 2(2): 12-13.

IUCN (2011). IUCN Red List of Threatened Species. Version 2011.2. <www.iucnredlist.org>. Downloaded on 13 March 2012.

Johnsgard, P.A. (1983). Cranes of the World. Indiana University Press, Bloomington, Indiana, 255pp.

Kanai, Y., M. Ueta, N. Germogenov, M. Nagendran, N. Mita \& H. Higuchi (2002). Migration routes and important resting areas of Siberian Cranes (Grus leucogeranus) between northeastern Siberia and China as revealed by satellite tracking. Biological Conservation 106: 339-346; http://dx.doi.org/10.1016/002075999399990

Meine, C.D. \& G.W. Archibald (eds.) (1996). The cranes: Status Survey and Conservation Action Plan. IUCN, Gland, Switzerland, and Cambridge, UK, 294pp.

Potapov, E. (1992). Some breeding observation on the Siberian White Crane Grus leucogeranus in the Kolyma lowlands. Bird Conservation International 2: 149-156.

Potapov, R.L. \& V.E. Flint (eds.) (1987). Birds of the USSR. Galliformes, Gruiformes. Nauka, Leningrad, 528pp. (In Russian).

Pshennikov, A.E., N.I. Germogenov, M.D. Tomshin, N.N. Egorov \& S.M. Sleptsov (2001). Lead poisoning of Siberian Cranes (Grus leucogeranus) in Yakutiya. Sibirski Ecoogocheskii Journal 1: 69-71. (In Russian).

Wu, G., J. de Leeuw, A.K. Skidmore, H.H.T. Prins, E.P.H. Best \& Y. Liu (2009). Will the Three Gorges Dam affect the underwater light climate of Vallisnaria spiralis L. and food habitat of Siberian Crane in Poyang Lake? Hydrobiologia 623: 213-222.

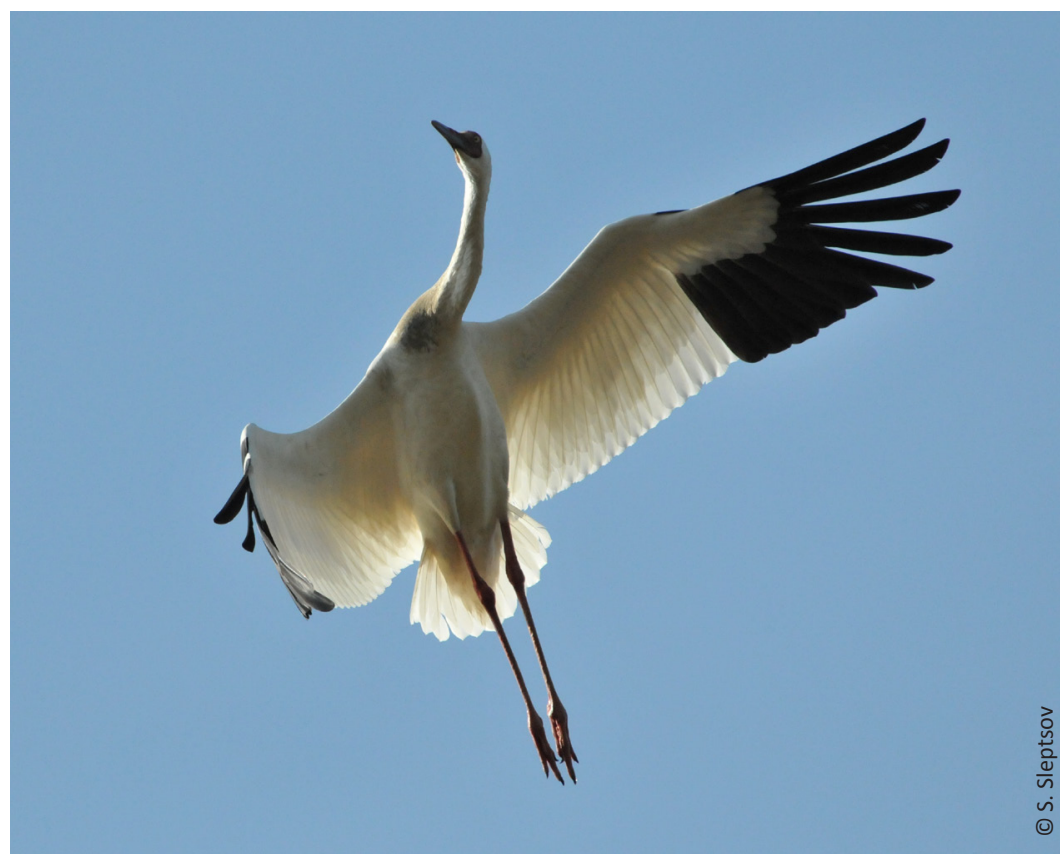

